\title{
CEREBRAL OXYGENATION AFTER RESUSCITATION WITH HEMOGLOBIN RAFFIMER
}

Gregory MT Hare MD PhD, Andrew J Baker MD, Elaine Liu, JL Wang, Nancy Sikich, C David Mazer MD

University of Toronto, St. Michael's Hospital, 30 Bond Street, Toronto, Ontario M5B 1W8.

INTRODUCTION: Morbidity and mortality associated with allogeneic blood transfusion and the reduced ability of stored blood to transport ox gen supports the development of hemoglobin based ox ygen carriers (HBOC). This study assesses the impact of hemorrhage and resuscitation with an HBOC (Hemoglobin raffimer, Hemolink ${ }^{\mathrm{TM}}$ ), fresh or stored blood on cerebral tissue ox ygen tension $\left(\mathrm{P}_{\mathrm{Br}} \mathrm{O}_{2}\right)$ and cerebral blood flow $(\mathrm{CBF})$ in rats.

METHODS: With animal Care Committee approval, an ox ygen sensing microelectrode and laser Doppler flow probe (Ox yLite and Ox yHo, Ox frd Optronix )was placed in the hippocampus of anesthetized rats (2\% isoflurane) to measure $\mathrm{P}_{\mathrm{Br}} \mathrm{O}_{2}$ and regional CBF. After establishing a baseline, $30 \%$ of the estimated blood volume $\left(20 \mathrm{ml}^{-1} \mathrm{~kg}^{-1}\right)$ was hemorrhaged. Thirty minutes later, resuscitation with an equivalent volume of hemoglobin raffimer, fresh or stored autologous blood ( 7 days, $\left.4^{\circ} \mathrm{C}, \mathrm{CPDA}-1\right)$ was performed ( $\mathrm{n}=6$ rats/group). Total hemoglobin concentrations (co-ox metry) and arterial blood gases (ABG) were measured (Radiometer). Data was analyzed by ANOVA and post hoc Tukey tests (Mean $\pm \mathrm{SD}$ ). Significance was assigned at $\mathrm{p}<0.05$.

RESULTS: No differences were observed between groups at baseline or following hemorrhage. After resuscitation, MAP increased in the hemoglobin raffimer group $(135 \pm 18 \mathrm{mmHg}, \mathrm{p}<0.05)$ relative to rats receiving fresh or stored autologous blood $(107 \pm 15$ and $93 \pm 18 \mathrm{mmHg}$, respectively). Post-resuscitation $\mathrm{P}_{\mathrm{Br}} \mathrm{O}_{2}$ values were higher in the fresh blood and hemoglobin raffimer group $(39.3 \pm 10.7$ and $35.4 \pm 10.7 \mathrm{mmHg}$, respectively, $\mathrm{p}<0.05)$, relative to the stored blood group $(21.5 \pm 4.4 \mathrm{mmHg})$. Normalized CBF increased after fresh blood resuscitation (2.0 $\pm 0.6, \mathrm{p}<0.05)$ but not after old blood or hemoglobin raffimer resuscitation $(1.2 \pm 0.1$ and $1.1 \pm$ 0.1 , respectively). All post-resuscitation co-ox metry and ABG values were similar, ex @pt for an increased methemoglobin content in the hemoglobin raffimer group $(2.4 \pm 0.9 \%, \mathrm{p}<0.05)$.

DISCUSSION: Hippocampal $\mathrm{P}_{\mathrm{Br}} \mathrm{O}_{2}$ was comparably increased by resuscitation with fresh autologous blood and hemoglobin raffimer. Increased $\mathrm{P}_{\mathrm{Br}} \mathrm{O}_{2}$ with hemoglobin raffimer was associated with elevated MAP and no increase in CBF. Post resuscitation cerebral hyperemia occurred with fresh, but not stored, blood. These data demonstrate limitations in cerebral ox yge delivery with transfusion of stored blood, relative to fresh blood and hemoglobin raffimer (AIRE, Hemosol Corp, CAS support). 